\title{
Small holder farmers coping strategies to household food insecurity and hunger in Southern Ethiopia \\ *Nigatu Regassa \\ doi: 10.4314/ejesm.v4i1.5
}

\begin{abstract}
This study has aimed at examining the small holder farmers' coping strategies to sustained household food insecurity and hunger in Southern Ethiopia (Sidama Zone). In order to collect the required input data, a comprehensive interview schedule was developed. The data were collected from 614 households who were selected through two-stage probability sampling technique. The association of each predicting variable and the dependent variable (coping strategies), controlling for all confounding factors, was examined using the multivariate analysis. The result revealed that about 54\% of the households were facing mild to severe food insecurity, and of which, about 19\% fall in household hunger category (as measured by Household Hunger Scale) for more than six months of the year. The study further showed that households in the study area employ a range of coping strategies to respond to the high and sustained food insecurity and hunger, ranging from minimizing the number of meals and amount of food consumption to out-migration of household members during chronic food shortage. The findings of the multivariate analysis using multiple regression technique documented that some demographic and socio-economic variable (such as age of the household head, educational status, access to main social service and others) have associations with the number of coping strategies practiced by the households. Finally, few recommendations were given based on the key findings of the study, which includes promoting income-generating activities, enhancing the micro-financing efficiency, creating employment opportunities at local areas to deter unskilled labor migration, on farm diversification and the like.
\end{abstract}

Key words: Climate change, food insecurity, copying strategies, Southern Ethiopia, Sidama Zone

\section{Introduction}

$\mathrm{t}$ is believed that agriculture is the
most susceptible sector to climate change. This is attributed to the fact that climate change affects the two most important direct agricultural production inputs, precipitation and temperature. Climate change also indirectly affects agriculture by influencing the emergence and distribution of crop pests and livestock diseases, exacerbating the frequency and distribution of adverse weather conditions, reducing water supplies and irrigation; and enhancing severity of soil erosion (McCarthy et al. 2001). These will have cumulative effects on household level food security status. Through time, pooor and hungry populations become less resilient to stress and disasters as they rely a great deal on the natural environment and lack the capacity and the resources required to recover from disasters (Oluoko et'al , 2011).

Societies are dynamic and they use all possible strategies to reduce the vulnerability to climate induced food insecurity. In the climate change literature, the Intergovernmental Panel on Climate Change (IPCC) identifies three components of climate vulnerability: exposure, sensitivity, and the capacity to adapt (McCarthy et al. 2001). Within this framework, the coping capacity is a dimension that cannot be neglected (Siri et al, 2005)

There are two kinds of responses to crisis, mainly resulting from food insecurity and hunger: coping mechanisms and adaptive capacity. Coping mechanisms are the actual responses to crisis on livelihood systems in the face of unwelcome situations, and are considered as short-term responses (Berkes \& Jolly 2001). Adaptive strategies are the strategies in which a region or a sector responds to changes in their livelihood through either autonomous or planned adaptation. Coping mechanisms may develop into adaptive strategies through times (Berkes \& Jolly 2001). Adaptation studies have often emphasized measures to reduce sensitivity by, for example, changing to forms of agriculture that are less climate sensitive, thus reducing the need for coping (Siri et al ,2005)

One of the most common methods for identifying food insecure households or regions is to look at the frequency and types of coping strategies as they are used to offset threats to a household's food and economic resources in times of hardship (Corbett, 1988). Studies in developing countries documented that households employ a range of coping strategies during sustained food insecurity and

* Associate Professor at Hawassa University, Institute of Environment, Gender and Development, 
hunger. For instance, the most important seasonal strategies include choice of cropping patterns to spread risks involving mixed cropping, cultivation of secondary crops, particularly root crops, off-farm income earning, selling productive assets, constricting food intake, and migration (Richard, 2009; Arun 2006); use of common property resources; changes in consumption patterns; share-rearing of livestock; and mutual support networks (Tony, 2009).

There is increasing demand for vulnerability and response assessments in view of identifying the susceptibility of populations to food insecurity. Studying household responses to climate induced food insecurity and hunger can also play an important role in improving our understanding of the impact of long-term climate change and of measures to facilitate adaptation. Previous studies of the coping strategies of smallscale farmers have argued that these strategies vary between households and also over time according to choices, objectives, opportunities and constraints (Siri et al, 2005). This study therefore aims at examining the level of household hunger and the responses (coping strategies) used by households in Sidama zone, Southern Ethiopia.

\section{The setting}

The Southern Nations, Nationalities and Peoples Region (SNNPR) is one of the states forming the federal government of the country. The region is divided into 13 zones and 133 districts that include 8 special woredas. According to the 2007 census, the population of the region is 15.3 million $(20 \%$ of the country's population), $92 \%$ of this population lives in rural area and the remaining $8 \%$ lives in urban area. The annual average population growth of the region is $2.9 \%$. About $49.1 \%$ is productive (15-64 years old) and from the productive population about 2.3 million $(15.4 \%)$ are farmers and pastoralists $(22 \%)$. The dependency ratio is $96.5 \%$. Average family size is 5.4 persons per household (CSA and Macro, 2006). The average population density in the region is 117 people per square kilometer, where the highest density is in Gedeo zone (536 person $/ \mathrm{km}^{2}$ ) and the lowest is in Omo zone (18 persons $/ \mathrm{km}^{2}$ ). The economy of the region is predominantly agriculture based, which is the major source of employment, revenue, export earning and livelihood. However, mismanagement and improper utilization of the natural resource base are not only threatening the productive capacity of the land and its resources, but also the socio-economic setting of the region, especially the rural communities (BoSP, 2006).

The Sidama zone is bordered in the south by the Oromia Region except for a short stretch in the middle where it shares a border with Gedeo, on the west by the Bilate River which separates it from Wolayita, and on the north and east by the Oromia Region. According to the recent census (CSA, 2007), the total population of the zone was 2,954,136, of which 1,491,248 are men and 1,462,888 women. With an area of 6,538.17 square kilometers, Sidama has a population density of 451.83. While $5.51 \%$ are urban inhabitants, $0.18 \%$ is pastoralists. The total households enumerated in 2007 were 592,539 which resulted in an average household size of 4.99 persons (CSA 2007). A substantial area of the Sidama land produces coffee, which is the major cash crop in the region, and the bulk of the population of the areas are known to heavily depend on 'enset' ( enset ventricosum). Like most part of the region, there are three distinct seasons in the zone, two rainy seasons and one dry season.

In a study conducted in the Boricha area of the Sidama zone (2006-2007), which is one of the lowland areas in the zone, it was observed that most of the pockets of the area are under continued human and climate induced impacts. The long stayed impacts has led to fragmentation of farmlands, reduction of fallow periods, shifts in cropping patterns, reduced time spent on farming, acceleration of land use conflict and competition, and land degradation (Assefach \& Nigatu 2006).

\section{Methodology}

The study was conducted in four selected rural villages in the Boricha Woreda of the Sidama Zone (Southern Ethiopia). The study generated the required data from primary sources collected from household heads and key informants in selected areas of the district. The sample size of 614 was estimated using the formula given by Woodward (1992) (see the annex).

The study employed two-stage probability sampling (combining the systematic and simple random sampling techniques) in selecting the 614 eligible households. The process of sampling started with the listing out 
of all kebeles in the study area. At the first stage, four kebeles were selected randomly. At the second stage, 150 household heads from the four villages (kebeles), were selected using systematic sampling technique.

Data were collected using structured questionnaire. A total of 10 data collectors were recruited and employed. The fieldwork took a total of 20 days (inclusive of three days training for data collectors). Upon completion of the fieldwork, the data were coded, entered into SPSS software, cleaned and verified. Household hunger was collected using the widely accepted tools developed by the Food and Nutrition Technical Assistance Project (FANTA). The nine question Household Food Insecurity Access Scale (HFIAS) that has been used in several countries (Coates et al, 2007). In the year 2011, based on empirical validation studies in selected African and Asian countries, the nine items are reduced to three questions to form the Household Hunger Scale (HHS). The HHS is used to assign households along a continuum of severity in food access from no hunger to severe household hunger (Deitchler et al, 2010). The types of coping strategies used by households were collected using a list of 16 different items, which is used to rank households according to the number of coping strategies used. In order to examine the relative importance of each independent variable, by controlling all the confounding factors, multivariate analysis in the form of multiple regressions was used. The multiple regression analysis is commonly used for the purpose of predicting values of one or more response variables form one or more predictor variables. The dependent variable of the study is the number of coping strategies used by households, a variable ranging from 0 (no coping strategies used) to 16 . The general formula of the multiple regression models is given by: $\mathrm{Y}_{\mathrm{i}}=\mathrm{B}_{\mathrm{o}}+\mathrm{B}_{1} \mathrm{X}_{1 \mathrm{i}}+\mathrm{B}_{2} \mathrm{X}_{2 \mathrm{i}}+$ $\ldots \ldots B_{K} X_{k i}+e$, Where $B$ stands for the coefficients, $\mathrm{K}$ denotes the number of predictor variables (factors explaining the dependent variables) and $\mathrm{i}$ denotes the $\mathrm{i}^{\text {th }}$ number of the sample population .

\section{Results}

Table 1 presents the background characteristics of respondents. The distribution of household size given on table 1 reveals that majority of the household $(45.1 \%)$ have size of 7-10 followed by 4-6 (31.4\%) and only 6.7 percent and 16.8 percent of the households have 0-3 and 10+ sized households respectively. The computed mean household size is 8.03 , which is well above the mean at national level (4.8).

The age distribution of the household head indicates that majority of them are in the age group $25-59(81.4 \%)$. The youth (15-24) and the aged $(60+)$ account for insignificant proportion of the respondents (6.8 and 11.7 percent respectively). The distribution on educational status of the respondents indicates that $44.1 \%$ of the respondents are found to be illiterate, while the remaining 55.9 percent achieved a certain level of education.

The majority of the respondents $(75.2 \%)$ are Protestant Christians followed by Catholic (9.3 $\%)$, traditional (4.7\%) Orthodox Christian (3.7 $\%)$ and the rest of the categories contribute smaller proportion of the respondents. The higher percentage distribution of the Protestant religion commensurate the regional picture where about 40 percent of the population of the region is Protestants (CSA and Macro, 2006). About 97 percent of the respondents were currently married while the remaining small proportions were either divorced or widowed. It is also seen that 24.8 percent of the female respondents were found to live in the polygamous marital arrangement where husbands have one or more additional wife during the survey date.

Information on household land ownership was also collected. As indicated on table 1 , the majority of the respondents $(73.8 \%)$ owned land size of less than one hectare. The remaining respondents reported land size of $1-2$ hectare $(20.7 \%)$, greater than 2 hectare $(2.4 \%)$ and $3.1 \%$ are found to be landless. The overall average land size computed for the study area is 0.84 hectare.

Table 2 lists nine important variables measured by dichotomous responses. The nine variables measure access to food ranging from "simple worry for food shortage" to "experience of spending the day and night without eating any food".

It is indicated on table 2 that 55.9 percent of the respondents reported to have worried about food shortage during the last four weeks; 73.1 percent reported inability to eat the preferred food: 74.3 percent reported to have eaten limited variety of food; 28 percent were unable to eat the preferred variety of food due to lack of adequate resources; 67.4 
percent reported that their household members eaten smaller amount of food; 62.9 percent missed the number of meals per day; 29.8 percent experienced ever no food to eat; 19.1 percent reported sleeping without eating food, and 12.5 percent reported to have spent the day and night without eating any food.

It is known that the level of household food insecurity and hunger can be measured by different ways depending on the purpose of a study. For, instance, the level of food insecurity can be measured by average number of available grain per person per year, daily caloric intake, and income level and like. Table 3 illustrates the Household Hunger Scale (HHS) computed by analyzing the last three questions in the HFIAS. In the HHS measure, the frequency responses for "sometimes" and "rarely" are combined while" often" remains as it is used in HFIAS version 3 . Then, by summing the categories of responses, the three major household hunger categories are produced as seen in table 3 . The HHS is meant to measure more severe food shortage.

Over all food insecurity level computed by taking the "frequency responses" in the main data is: $54.1 \%$, which indicates that more than half of the study households face mild to severe food insecurity. This figure is reduced significantly when more sustained household hunger is computed (see Table 3), where $28.8 \%$ of the households fall in mild to severe level of household hunger during the survey time.

Table 4 presents a range of coping mechanisms reported by respondents which includes: minimizing the number of meals and amount of food consumption $(60.3 \%)$ using buffer stock ( $59.6 \%$ ) ; diversifying livelihood ( $43.3 \%$ ) cultivating more crops ( $42 \%$ ) wage labor ( $34.9 \%$ ) seasonal migration to neighboring community during peak season ( $34.4 \%)$.inter cropping ( $49.5 \%$ ) and others (see table 4).

Table 5 presents the results of the multivariate analysis of the key determinants of coping strategies used by households to ensure access to food. It is seen that household size (sometimes approximated by the total number of children) and the number of coping strategies used are positively related, i.e. the larger the household size the more the number of coping strategies employed. Put it differently, other factors remaining constant, an increase of one household would results in an increase of the number of coping strategies by 0.39 units. Similarly, an increase of one unit in the age of household head results in an increase in the number of coping strategies by 0.408 units, indicating positive relationship.

In increase of one unit in land size results in a decrease in the number of coping strategies by 0.489 units, suggesting that the two variables are negatively related. The relationship between households' access to major social services and the level of coping strategies used has become significant (B $=.010$ and $\mathrm{P}=0.27$ ). An increase in accessibility by one unit results in an increase of the number of coping strategies by 0.010 . The strongest negative relationship is established between the educational status of household head and the coping strategies used. It is seen from table 5 that a one unit increase in the level of education results in decline of the number of coping strategies by 0.194 units.

\section{Discussion}

The study addressed two important issues: measuring the level of household food insecurity using some acceptable tools and examine the responses of households to food insecurity and hunger in rural Sidama, Southern Ethiopia.

A wide variety of methodological approaches have been applied to food security studies, determined by the purpose of the analysis, availability of data, and the background and preference of analysts. Most household food security measurements are a collection of direct and indirect indicators reflecting food supply, food access and outcome indicators (Siri et al, 2005).This study employed commonly known measures of food security status used cross culturally: Household Food Insecurity Access Scale, HFIAS and its recent modified version Household Hunger Scale (HHS). The results revealed that about $54.1 \%$ of the households in the study area are found to be food insecure, and $28.8 \%$ of the households fall in mild to severe level of household hunger for an extended period of time during a year.

Using the HFIAS measure, it was possible to observe how much food security is a concern by the community members. For instance, for the simple emotional insecurity questions (worrying about adequacy of food supply), quite good proportion of the 
respondents $(55.9 \%)$ reported that they do worry about the sources and amount of food their family members get in the days to come. This emotional part prevails when one is not sure of the consistency of where each meal is going to come for children and elderly persons in the household. It is also shown that large proportions of the respondents are not meeting society norms of eating - acceptability of food. The most striking results of the analysis using the HFIAS (see the last three responses on table 3) is that quite good proportion of them miss meals and sleep without food, suggesting that there are cases of periodic hunger:

In such chronic food shortage and periodic hunger, which is repeated over years due to human and climatic impacts, the people in the study areas had to use certain coping strategies to reduce their vollenerability. For the purpose of this study, the concept of coping strategies is used to mean any action aimed at obtaining food or income during times of stress, either through production or through formal and informal exchange and claims. Coping strategies can be characterized as relating to production (agricultural and economic), social adjustments (reciprocal economic exchange), and biological strategies, including changing the diet or reducing consumption.

The information on the type of coping strategies used by households was collected using a long list of strategies developed through literature review. The results of the study revealed that households use a number of coping strategies ranging from one or more principal coping strategies to various complementary strategies; switching between principal and complementary activities during chronic food shortage. A principal coping strategy is characterized by providing a main source of food and income for a household, substituting for farming which is relatively regular and reliable, while complementary coping strategies are opportunistic and often irregular, providing some food or income for shorter time periods. As the informal discussion held with the community members indicates, complementary coping strategies are used when no principal coping strategy was available or failed.

Some of the most commonly used complementary coping strategies in the study area are minimizing the number of meals and amount of food consumption (60.3\%) using buffer stock ( $59.6 \%$ ) ; diversifying livelihood ( $43.3 \%$ ) ; cultivating more crops ( $42 \%$ ); wage labor ( $34.9 \%$ ); seasonal migration to neighboring community during peak season ( $34.4 \%$ ) and inter cropping ( $49.5 \%$ ). Similar studies in other part of Africa have also showed nearly the same result. A study conducted in three most deprived and povertystricken regions in the Northern parts of Ghana showed that households use a wide range of mechanisms and communal support networks to cope with the situation which includes collection of wild foods, market purchases, inkind (food) payment, support from relatives and friends, sales from livestock and household valuables, migration and wage labor, reduction in the number of meals served each day, reduction in the portions/ sizes of meals and consumption of less preferred foods ( Wilhemina,2008). A recent study conducted in Southern Sudan has identified some common coping mechanisms used by the small holder farming communities, which includes eating immature crops, reducing the size and number of meals, consuming lesspreferred foods, increasing collection and consumption of wild foods (Ververs,2010 ). A study in informal settlement in South Africa has also listed commonly used coping strategies: cooking a limited variety of foods, maternal buffering by limiting the caregiver's intake to make food available for the children, skipping of meals and limiting portion sizes (Wilna, 2006)

The regression output indicates that there are certain household level variables affecting the magnitude of coping strategies used by the households in the study area. Among the variables entered into the multiple regression analysis, five of them have become significantly associated with the dependent variable (coping strategies).

The study has found that there is positive relationship between household size/ number of children/ and the level of coping strategies used. It is generally understood that that children in many developing countries, including ours, participate in various social, cultural, religious, and economic activities. In traditional subsistence agrarian economy, particularly in patriarchal society like in most communities of Ethiopia, children are considered very instrumental as economical and non-economic resources of a family unit 
who generate income to the household. The positive relationship between age of the household head and the number of coping strategies used has mainly emanated from the fact that older men usually have larger number of children under the study context.

There are good reasons to believe that educational attainment negatively affects the number of coping strategies used. First, people with better educational status usually engage in more sustained but few coping strategies. Second, when education level increases, there is likelihood that the household shifts its portfolio and stick to more non agricultural activities. As expected, the result of the regression analysis has documented negative relationship between land size and number of coping strategies. It is assumed that households with small plots of land do not normally wish to diversify their income by basing on such small land, and rather more preferably use other multiple complementary strategies (such as temporary wage, petty trading, seasonal migration, food aid...etc). On the contrary, households with larger land size prefer to use fewer, but more rewarding, strategies of inter-cropping and cash cropping to increase income.

The study has also found positive relationship between accessibility to major social service, which is measured by composing the reported minutes/hours each respondent reported to take to reach the nearest facilities, and the number of coping strategies employed. Needless to mention that it is more affordable to employ various coping strategies in a situation where households have transport outlets and other facilities (such as mini market, credit services, big markets...etc).

\section{Conclusion}

The present study has documented that there is comparably high level of climate induced household food insecurity among the study population. It is also seen that households in the study areas employ a variety of principal and complementary coping strategies ranging from minimizing the number of meals and amount of food consumption to migration of household members. It is proved that, in the midst of serious food scarcity and insecurity, the coping strategies employed are playing a mediating role for households' access to a wide range of livelihood resources and serving as a gateway to livelihood security. It is also observed that the number of coping strategies used are strongly associated with some household and individual level variables discussed above.

Therefore, based on the key findings of the study, the author calls for short term and long term intervention programs to reverse/reduce the precarious situation resulted from human and climatic impacts. As part of short-term intervention programs, it is important that actions should be taken to alleviate the chronic food shortage by expanding safety net programs so as to enable the poorer households have an adequate entitlement of food, availing and ensuring effective level of fertilizer input under increasing land scarcity ( use of organic fertilizer should also considered since it provides a comparative advantage for the country due to its ease availability, less cost, better yield, better long-term restoration of soil fertility and moisture). As part of the long run strategy, the local government may use broadbased intervention programmes including ensuring compulsory primary school education and adult education, skills training to women and youth members of the community; income-generating activities and enhancing the micro-financing efficiency, creating employment opportunities at local areas to deter unskilled migration of household members and sustainable/well planned resettlement programs.

Finally, due to the temporary and diverse nature of the coping strategies used, none of them may be used for intervention across the communities until efforts are made to change these practices into more sustained adaptive strategies to overcome the future likely climate change impacts. 


\section{References}

Arun K.C and Keshav Lall M. (2006) Food Insecurity and Coping Strategies in Rural Areas of Nepal:A Case Study of Dailekh District in Mid Western Development Region. Journal of International Development and Cooperation, Vol.12, No.2, 2006, pp. 25-45

Asefach and Nigatu (2006). Correlates of Household Food Security in Densely Populated Areas of Southern Ethiopia: Does the Household Structure Matters. Journal of Home and Community Sciences. Vol 1 (2): pp85-91.

Berkes, F. \& Jolly, D (2001) Adapting to climate change: social-ecological resilience in a Canadian western Arctic community. Conservation Ecology, 5(2), 18.

Bureau of Statistics and Population, BoSP. (2006). Five Years Plan of the SNNPR on Population and Development, Hawassa.

Coats , Janifer, Anne Swindale and Paul Blinsky. ( 2007) .Household food insecurity Access Scale, FSI, for measurement of household food acess : Indicator Guide (V.3). Washington D.C : Food and Nutrition Technical Assistance Project ,Acacademy for Educatinsl Development.

Corbett, Jane, "Famine and Household Coping Strategies," World Development, Vol. 16, No. 9, 1988, pp. 1099-1112.

Central Statistics Authority, CSA (2007). Summary and Statistical Report of the 2007 Population and Housing Census Results. Addis Ababa.

CSA (Ethiopia) and ORC Macro (2006). Reported on 2005 Ethiopian demographic and health survey Addis Ababa, Ethiopia and Calverton, Mary land USA

Deitchler, M, Ballard T, Swindale A, and Coates J (2010). Validation of a Measure of Household Hunger for Cross-Cultural Use. Washington D.C : Food and Nutrition Technical Assistance II Project (FANTA II),Acacademy for Educational Development. McCarthy J J, Canziani O F, Leary N A, Dokken D J and White K S eds 2001 Climate change 2001: impacts, adaptation and vulnerability Cambridge University Press, Cambridge

Oluoko-Odingo and Alice Atieno (2011). Vulnerability and Adaptation to Food Insecurity and Poverty in Kenya. Annals of the Association of American Geographers. Jan 2011, Vol. 101 Issue 1, pp1-20. Blackmail publishing.

Richard Longhurst (2009). Household Food Strategies in Response to Seasonality and Famine. IDS Bulletin: Vol.17,No 3, pp 27-35, July 1986

Tony Beck (2009); Survival Strategies and Power amongst the Poorest in a West Bengal Village.Vol.20,no 2, pp 23-32,

Siri H Eriksen N., Katrina B. \& Mick P. K (2005). The dynamics of vulnerability: locating coping strategies in Kenya and Tanzania. The Geographical Journal, Vol. 171, No. 4, December 2005, pp. 287-305

Smithers J and Smit B (1997). Human adaptation to climatic variability and change Global Environmental Change 7 129-46

Woodward,M.(1992) Formula for sample size, power and minimum Detectable Relative Risk in Medical Studies. The Statistician, Vol 41(2):185-196

Wilhemina Quaye (2008). Food security situation in northern Ghana, Coping strategies and related constraints. African Journal of Agricultural Research Vol. 3 (5), pp. 334-342, May, 2008

Ververs, Mija-tesse. Situation Analysis of Nutrition in Southern Sudan: Analysis Based on June 2009 Assessment. Washington, DC: AED/Food and Nutrition Technical Assistance II Project (FANTA-2), 2010.

Wilna H. Oldewage-Theron, Emsie G. Dicks and Carin E. Napier (2006). Poverty, household food insecurity and nutrition: Coping strategies in an informal settlement in the Vaal Triangle, South Africa. Public Health. Vol.120 (9): 795-804

\section{Acknowledgement}

This research work was funded by the Center for Environment and Society (CES), Hawassa University. The authors thus would like to thank the project coordinator, Dr. Ferdu Azerefegn, for timely facilitation of the fund and keen encouragements during the research period. 


\section{Annex : Sample size estimation}

Sampling size $(\mathrm{n})=\frac{\mathrm{P}(1-\mathrm{P}) \mathrm{Z}^{2}}{\mathrm{e}^{2}}+5 \% \quad \begin{gathered}\text { Where } \mathrm{P}=0.35, \mathrm{e}=0.05 \\ \mathrm{Z}=1.96\end{gathered}$

Where $\mathrm{Z}$ is the upper $\alpha / 2$ points of standard normal distribution with $\alpha=0.05$ significance level, which is $Z=1.96, \mathrm{~d}$ is the degree of precisions, $\mathrm{p}$ is proportion of food insecure households (which is taken from previous studies as 0.5 or $50 \%$ ). Since eligible households are not directly selected, the calculated sample size should be adjusted for design effect (D).The design effect is generally assumed to be 1.5 .As a result, the required sample size can be obtained by $\mathrm{n} \times \mathrm{D}$ which is about 594 households. With additional contingency of 20 households, the final interviewed households were 614.

Table 1. Percentage distribution of respondents by selected background characteristics $(n=614)$.

\begin{tabular}{|c|c|c|}
\hline Characteristics & Frequency & Percentage \\
\hline \multicolumn{3}{|l|}{ Household size } \\
\hline $0-3$ members & 41 & 6.7 \\
\hline $4-6$ & 193 & 31.4 \\
\hline $7-10$ & 277 & 45.1 \\
\hline 10 and above & 103 & 16.8 \\
\hline \multicolumn{3}{|l|}{ Age } \\
\hline Age $15-24$ & 42 & 6.8 \\
\hline $25-59$ & 500 & 81.4 \\
\hline 60 and above & 72 & 11.7 \\
\hline \multicolumn{3}{|l|}{ Education Status } \\
\hline Elementary ( 1-6) & 218 & 35.5 \\
\hline Junior ( 7- 8) & 77 & 12.5 \\
\hline Secondary (9-12) & 41 & 6.7 \\
\hline College diploma & 7 & 1.1 \\
\hline Illiterate & 271 & 44.1 \\
\hline \multicolumn{3}{|l|}{ Religion } \\
\hline Orthodox Christian & 23 & 3.7 \\
\hline Catholic & 57 & 9.3 \\
\hline Protestant & 462 & 75.2 \\
\hline Muslim & 22 & 3.6 \\
\hline Traditional & 29 & 4.7 \\
\hline Others & 21 & 3.4 \\
\hline \multicolumn{3}{|l|}{ Marital Status } \\
\hline Divorced & 10 & 1.6 \\
\hline Widowed & 10 & 1.6 \\
\hline Married & 594 & 96.7 \\
\hline \multicolumn{3}{|l|}{ Marital form } \\
\hline Polygamous & 152 & 24.8 \\
\hline Monogamous & 462 & 75.2 \\
\hline \multicolumn{3}{|l|}{ Land holding } \\
\hline Landless & 19 & 3.1 \\
\hline Less than one hectare & 453 & 73.8 \\
\hline $1-2$ hectares & 127 & 20.7 \\
\hline greater than two hectares & 15 & 2.4 \\
\hline
\end{tabular}


Table 2. Percentage distribution of sample households by food security status Indicators $(\mathrm{n}=614)$

\begin{tabular}{|l|l|l|}
\hline Indicators & Yes & No \\
\hline Worry about food insecurity for the last 4 weeks & 55.9 & 44.1 \\
Inability to eat the preferred food in the last four weeks & 73.1 & 26.9 \\
Availability of limited Varity of food due to lack of resource in the & 74.3 & 25.7 \\
household & & \\
Ability of household to get the preferred type of food & 28.0 & 72.0 \\
Availability of smaller amount of meal in the past four week & 67.4 & 32.6 \\
Missing the number of meals per day for the past four weeks & 62.9 & 37.1 \\
Ever no food to eat in the past four weeks & 29.8 & 70.2 \\
Sleeping without eating any food in the past four weeks & 80.1 \\
Spending the day and night without eating any food in the past four & 12.5 & 87.5 \\
weeks & & \\
\hline
\end{tabular}

Table 3. Percentage distribution of sample households by hunger status $(n=614)$.

\begin{tabular}{|l|l|}
\hline \multicolumn{1}{|c|}{ Status } & Percent \\
\hline No household hunger & 62.4 \\
\hline Mild household hunger & 18.4 \\
\hline Moderate to severe hunger & 10.4 \\
\hline
\end{tabular}

Table 4 Percentage distribution of respondents by reported coping strategies $(n=614)$

\begin{tabular}{|l|l|l|l|}
\hline Variables & No food shortage & Yes & No \\
\hline $\begin{array}{l}\text { Member of the household migration seeking for job } \\
\text { opportunity }\end{array}$ & 9.6 & 23.1 & 67.3 \\
Petty trading & 9.1 & 33.7 & 57.2 \\
Cultivating more of cash crop & 10.7 & 42.0 & 47.2 \\
Selling charcoal & 12.2 & 6.2 & 81.6 \\
Selling fire wood & 11.2 & 21.0 & 67.8 \\
Selling cultural items & 13.0 & 6.4 & 80.3 \\
Getting remuneration from migrated household & 13.7 & 14.5 & 71.8 \\
members & & & \\
Inter-cropping & 11.1 & 49.5 & 39.4 \\
Using local saving mechanism & 12.5 & 27.2 & 60.3 \\
Neighborhood resource exchange mechanism & 13.2 & 21.0 & 65.8 \\
Using food aid & 11.4 & 31.4 & 57.2 \\
Using wage labor & 9.6 & 34.9 & 55.5 \\
Using seasonal migration to neighboring community & 12.5 & 34.0 & 53.4 \\
during peak season & & & \\
Diversifying livelihood & 12.1 & 43.3 & 44.6 \\
Using buffer stock & 10.4 & 59.6 & 30.0 \\
Minimizing the number of meals and amount of food & 10.6 & 60.3 & 29.2 \\
consumption & & & \\
\hline
\end{tabular}


Table 5. Results of multiple regression for association between coping strategies used by households and selected explanatory variables $(n=614)$.

\begin{tabular}{|c|c|c|c|}
\hline & $\mathrm{B}$ & S.E & Sig \\
\hline (Constant) & 5.827 & & .000 \\
\hline Household size & .390 & .164 & $.051 * *$ \\
\hline Age of household head & .408 & .031 & $.004 * *$ \\
\hline Proportion of working adult persons & .199 & .198 & .315 \\
\hline Land size owned by the household & -.489 & .230 & $.034 * *$ \\
\hline Access to service index & .010 & .005 & $.027 * *$ \\
\hline $\begin{array}{l}\text { Educational status of the household } \\
\text { head }\end{array}$ & -.194 & .055 & $.000 * *$ \\
\hline Type of religion & -.507 & .143 & .102 \\
\hline $\begin{array}{l}\text { Marital form } \text { (polygamous } \mathrm{Vs} \\
\text { monogamous) }\end{array}$ & -.038 & .302 & .900 \\
\hline \multicolumn{4}{|c|}{$\begin{array}{l}\text { Dependent variable is the number of coping mechanisms used by households } \\
\mathrm{N}=614 ; \mathrm{R}^{2}=0.23 \\
* * *=\text { Sig. at } 1 \% ; * *=\text { Sig at } 5 \%\end{array}$} \\
\hline
\end{tabular}

